\title{
Myelodysplastic Syndrome Complicated with Inflammatory Intestinal Ulcers: Significance of Trisomy 8
}

\author{
Hiroshi Kawabata ${ }^{1}$, Toshioki Sawaki ${ }^{1}$, Takafumi Kawanami ${ }^{1}$, Kumiko Shimoyama ${ }^{1}$, \\ Hiromi Karasawa ${ }^{1}$, Toshihiro Fukushima ${ }^{1}$, Yasufumi Masaki ${ }^{1}$, Noriyoshi Ogawa ${ }^{1}$, \\ Yuko Hirose ${ }^{1}$, Kazuaki Ozaki ${ }^{1}$, Koshi Shimanaka ${ }^{2}$, Shujiro Takase ${ }^{2}$, \\ Hiroshi Ueno ${ }^{3}$ and Hisanori Umehara ${ }^{1}$
}

\begin{abstract}
Three cases of myelodysplastic syndrome (MDS) complicated with inflammatory intestinal ulcers all had cytogenetic abnormalities with trisomy 8. The first two patients were diagnosed with intestinal Behçet's disease and were successfully treated with salazosulphapiridine, and the third patient died after leukemic transformation. We review the reported cases of MDS complicated with Behçet's disease. Most of these cases are Japanese, having intestinal involvement as well as cytogenetic abnormalities with trisomy 8 . We discuss the significance of trisomy 8 in intestinal involvement in MDS.
\end{abstract}

Key words: Behçet's disease, cytokines, leukemia

(DOI: 10.2169/internalmedicine.45.1718)

\section{Introduction}

Myelodysplastic syndrome (MDS) is the term for a group of clonal hematologic disorders with impaired cell differentiation (1). In MDS, anemia, thrombocytopenia and/or neutropenia are common manifestations, which may cause heart failure, life-threatening hemorrhage and serious infection. Cytogenetic abnormalities of bone marrow cells such as monosomy 7 and trisomy 8 can frequently be found in patients with MDS. We recently encountered three cases of MDS complicated with inflammatory intestinal ulceration; all of these cases had fever, massive melena and multiple ulcerations in the iliocecal region, and on bone marrow examination, cytogenetic abnormalities with trisomy 8 were present. Two were diagnosed with intestinal Behçet's disease (BD).

BD is a chronic inflammatory disorder characterized mainly by recurrent oral aphthae, genital ulcers, uvenitis and skin lesions. In some cases, vasculitis and inflammation of the gastrointestinal tract or central nervous system occurs.
We describe these three cases and discuss the significance of this chromosomal abnormality, trisomy 8 , in the intestinal involvement in MDS, especially in association with BD.

\section{Case Report}

\section{Case 1}

A 76-year-old woman was referred to our hospital for severe anemia. Bone marrow examination revealed that her marrow was hypoplastic, and megakaryocytic dysplasia as well as emperipolesis of neutrophils within megakaryocytes were observed (Fig. 1, panel a). The karyotype of her bone marrow cells was $47 \mathrm{XX},+8$. She was diagnosed with MDS and refractory anemia (RA) in the French-American-British classification. She had been treated with metelonone, an anabolic steroid, and occasional red blood cell transfusion. Recurrent oral aphtha occurred when she was 79. She was admitted to our hospital for severe abdominal pain and highgrade fever when she was 80 . A blood test showed severe anemia with a red blood cell count of $1.81 \times 10^{6} / \mu 1$, hemoglo-

\footnotetext{
${ }^{1}$ The Department of Hematology and Immunology, Kanazawa Medical University, Ishikawa, ${ }^{2}$ the Department of Gastroenterology, Kanazawa Medical University, Ishikawa and ${ }^{3}$ the Department of Internal Medicine, Himekawa Hospital, Itoigawa

Received for publication January 16, 2006; Accepted for publication August 9, 2006

Correspondence to Dr. Hiroshi Kawabata, the Department of Hematology and Oncology, Graduate School of Medicine, Kyoto University, Kyoto 606-8507
} 


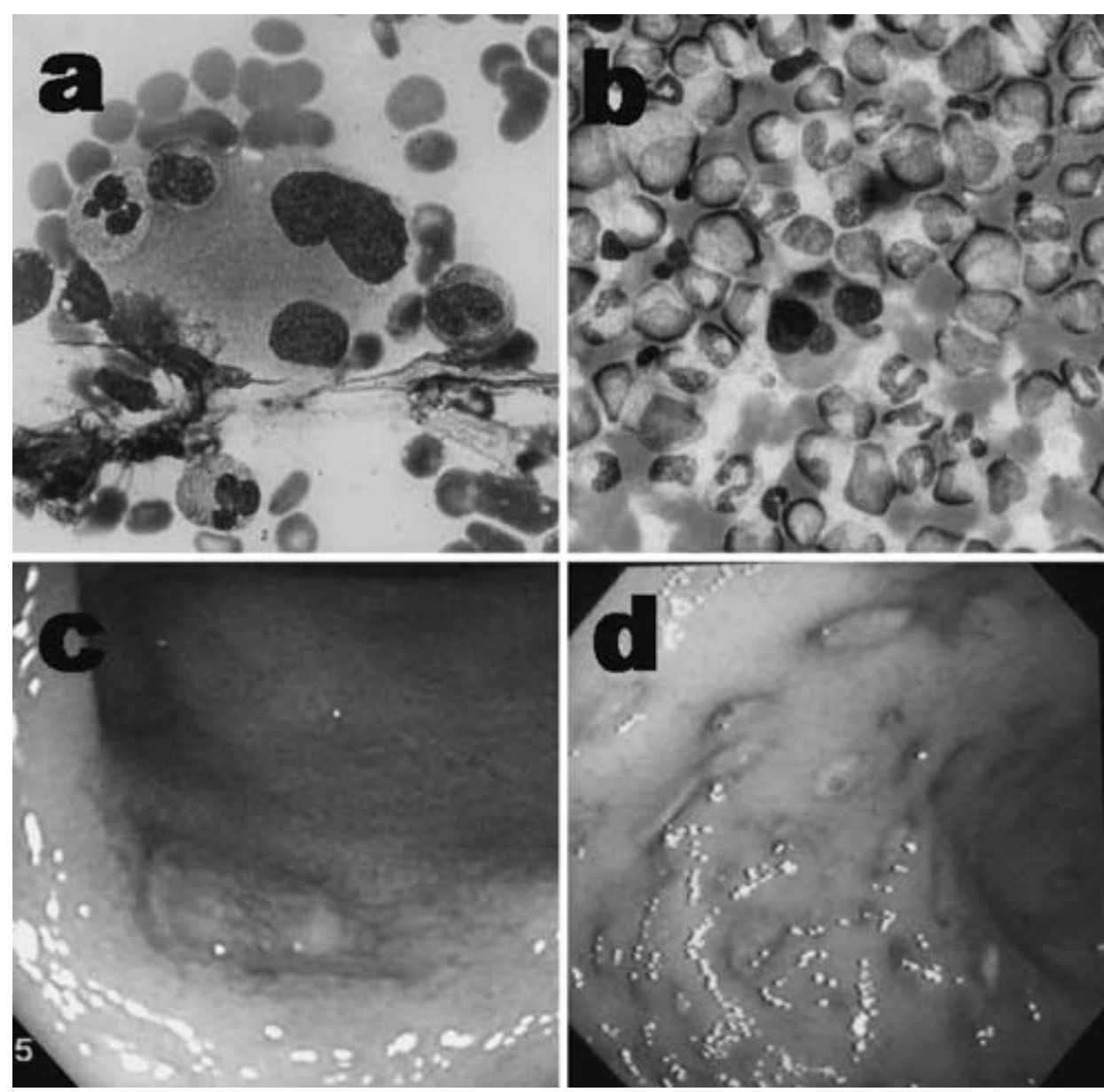

Figure 1. Panel a: Megakaryocytic dysplasia with emperipolesis of neutrophils observed in the bone marrow in Case 1 (original magnification, $\times 400$ ). Panel b: Hyperplastic marrow with megakaryocytic dysplasia observed in Case 2 . In panels a and b, the original magnification was $\times 400$. Panels $\mathrm{c}$ and $\mathrm{d}$ : Intestinal ulcers observed in the cecum in Cases 2 and 3, respectively.

bin $(\mathrm{Hb})$ of $5.7 \mathrm{~g} / \mathrm{dl}$ and hematocrit of $18.3 \%$. C-reactive protein (CRP) was elevated to $18.0 \mathrm{mg} / \mathrm{dl}$. Endoscopic examination of her gastrointestinal tract revealed multiple ulcers in the ileocecal region. Histopathologic examination of these ulcers showed non-specific inflammation. She had HLA-B51. Taken together, she was diagnosed with intestinal BD. Her pathergy test was negative. Despite intensive treatment with antibiotics, recurrent attacks of abdominal pain, melena, and fever persisted during the following year. After the administration of salazosulphapiridine, her abdominal symptoms were gradually diminished.

\section{Case 2}

A 75-year-old man was admitted to our hospital for highgrade fever and abdominal pain. He had had a sore throat and recurrent oral aphthae for 5 months before admission. On admission, his body temperature was elevated to $39.5^{\circ} \mathrm{C}$. His blood test showed that $\mathrm{Hb}$ was $12.2 \mathrm{~g} / \mathrm{dl}$, white blood cell count was $16,600 / \mu 1$, platelet count was $199,000 / \mu 1$ and CRP was $16.7 \mathrm{mg} / \mathrm{dl}$. He had aphthae on his tongue, folliculitis on his skin, and genital ulcers. His pathergy test was positive. He was diagnosed with $\mathrm{BD}$, and antibiotics and colchicine were administered. Despite this treatment, the high-grade fever accompanied with abdominal pain, oral aphthae and skin lesions recurred 3 times during the subsequent 7 months. Interestingly, each attack began with the sudden onset of a high-grade fever accompanied by slight thrombocytopenia and marked elevation of CRP and serum creatinine kinase (CK) levels. After treatment with antibiotics, CRP and CK levels decreased rapidly, the platelet count overshot, and erythema nodosum as well as oral aphthae appeared, followed by melena (Fig. 2). Seven months after his first admission, he had an attack of fever and abdominal pain with massive melena. Endoscopic examination of his gastrointestinal tract revealed multiple ulcers in the ileocecal region (Fig. 1, panel c). As his anemia ( $\mathrm{Hb} 5.2 \mathrm{~g} / \mathrm{dl}$ ) at this point was slightly macrocytic, we performed a bone marrow examination, which revealed marked myeloid hyperplasia with increased blast cells and a karyotype of $47 \mathrm{XY}+8$ (Fig. 1, panel b). He was diagnosed with MDS and refractory anemia with excess blasts (RAEB). After treatment with intravenous hyper-alimentation and salazosulphapiridine, his BD symptoms disappeared. 


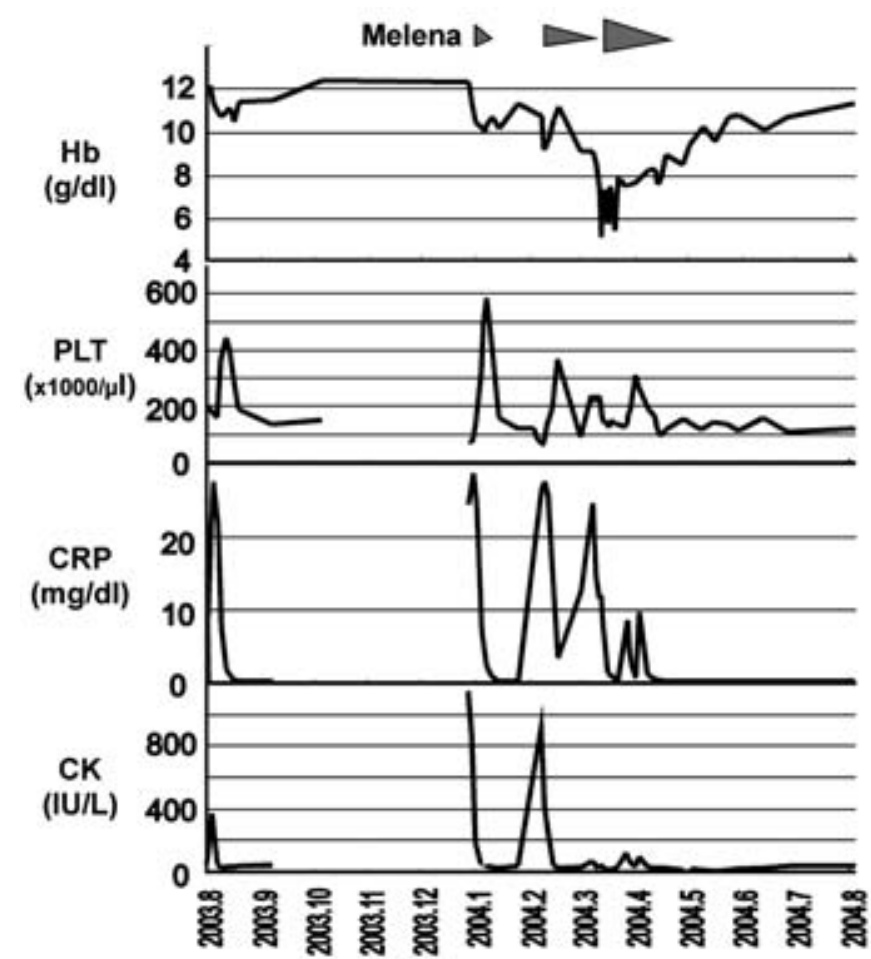

Figure 2. Clinical course of Case 2. Each attack began with a high-grade fever, erythema nodusa, elevation of C-reactive protein (CRP) and creatinine kinase (CK) levels as well as a slight decrease in platelet (PLT) counts. In each attack, administration of antibiotics quickly normalized the levels of CRP and CK, and the PLT count overshot. Oral and genital aphthae as well as melena occurred subsequently. After the last episode of melena, salazosulphapiridine was started. Colchicine was continued throughout the course shown in this figure.

\section{Case 3}

A 67-year-old woman was admitted to our hospital for diarrhea, nausea and vomiting. As she had anemia, thrombocytopenia and leukocytosis, we performed a bone marrow examination, which showed myeloid hyperplasia with trilineage dysplasia and an increase of blasts. She was diagnosed with MDS and RAEB. The karyotype of her bone marrow cells showed complex abnormality with trisomy 8 . Endoscopic examination of her gastrointestinal tract revealed multiple ulcers in the ileocecal region (Fig. 1, panel d). Histopathologic examination of the ulcers showed nonspecific inflammation. She had intractable oral aphthae. Despite intensive treatment with antibiotics, colchicine, salazosulphapiridine and intravenous hyperalimentation, attacks of fever with massive melena recurred at short intervals. Eight months after the initial diagnosis of MDS, blast cells increased in her peripheral blood, indicating leukemic transformation. She died of leukemia with uncontrollable bacterial and fungal infection two months after leukemic transformation.

Discussion

More than 30 MDS cases complicated with inflammatory intestinal lesions have been reported to date. Most cases have been classified as intestinal BD, while some have been diagnosed as Crohn's disease or ulcerative colitis (2-13). The reported cases of MDS complicated with BD are listed in Table 1 . The majority was the incomplete type with intestinal involvement, especially in the iliocecal region, and trisomy 8 was a very common chromosomal abnormality. Interestingly, most of these reports are from Japan, suggesting the importance of the regional or racial background in this clinical condition. The incidence of BD itself is endemically high in Turkey, Iraq, Iran, Korea and Japan; these populations were derived historically from the ancient Silk Road (14). HLA-B51, one of the common allele types among Japanese, has been implicated in the higher occurrence of BD in Japanese. In Japanese living in Hawaii, the frequency of $\mathrm{BD}$ is very low, therefore some environmental factors in addition to inherited factors may be important for the occurrence of $\mathrm{BD}$ (15). Among the present three cases, only Case 1 had HLA-B51. Together with the reported cases, trisomy 8 seems to be a much more important risk factor for BD rather than HLA-B51 in patients with MDS. The order of onset of MDS and BD varies. In some cases, the diagnosis of MDS preceded the manifestation of BD symptoms. In other cases, MDS developed years after the onset of BD symptoms; three of these cases had been treated with chlorambucil, which could induce secondary MDS, for $\mathrm{BD}$ (16-18). In the present three cases, the diagnosis of BD was preceded by the diagnosis of MDS in Case 1, which was reversed in Case 2. In Case 3, both intestinal symptoms and hematological abnormalities co-existed at her first visit. As for treatment, Kuttikat et al reported a case of steroidrefractory BD associated with MDS with trisomy 8, whose symptoms were significantly improved by thalidomide, an immunomodulating agent, although it had to be discontinued due to peripheral neuropathy (19). Two relatively young cases had cord blood transplantation and achieved remission of both MDS and BD $(20,21)$.

Among the present cases, Cases 1 and 2 were diagnosed as BD, and were successfully treated with salazosulphapiridine. In Case 2, each attack was accompanied by an elevated serum CK level, suggesting the presence of myositis in the acute phase (Fig. 2). Antibiotics seemed effective, at least transiently, in each attack in Cases 1 and 2 in terms of fever and CRP elevation, but were not effective for oral aphthae or melena. Bacterial infection which could trigger an overreaction of the immune system might have caused mucosal and skin lesions in these cases. Case 3 did not fulfill the criteria of either BD or inflammatory bowel diseases, but similar to the other cases, had intractable oral aphthae as well as inflammatory intestinal ulcers in the iliocecal lesion with recurrent melena, indicating a pathologic condition 
Table 1. Reported Cases of MDS Complicated with BD

\begin{tabular}{|c|c|c|c|c|c|c|c|c|}
\hline \multirow[b]{2}{*}{ Age } & \multirow[b]{2}{*}{ Sex } & \multicolumn{2}{|l|}{ MDS } & \multirow[b]{2}{*}{$B D$ onset } & \multicolumn{3}{|l|}{$\mathrm{BD}$} & \multirow[b]{2}{*}{ Ref } \\
\hline & & type & Karyotype & & symptoms & Country & Others & \\
\hline 72 & $M$ & RA & $+8, \operatorname{drl}(20)(q 11)$ & 1.6y after MDS & $\mathrm{O}, \mathrm{G}, \mathrm{S}, \mathrm{F}$ & Japan & & (2) \\
\hline 35 & $M$ & RA & normal & 3y after MDS & $\mathrm{O}, \mathrm{G}, \mathrm{S}, \mathrm{U}, \mathrm{A}$ & Japan & & (3) \\
\hline 57 & M & RA & +8 & $6 \mathrm{~m}$ after MDS & $\mathrm{O}, \mathrm{G}, \mathrm{I}, \mathrm{S}, \mathrm{F}$ & Japan & & (3) \\
\hline 52 & M & RA & $+22, \mathrm{t}(9 ; 22)(\mathrm{q} 34 ; \mathrm{q} 11)$ & $4 y$ after MDS & $\mathrm{O}, \mathrm{S}, \mathrm{A}, \mathrm{F}$ & Japan & & (3) \\
\hline 59 & $M$ & RAEB & Complex with $-5,-7,+8$ & $4 \mathrm{~m}$ after MDS & $\mathrm{O}, \mathrm{F}, \mathrm{U}, \mathrm{A}, \mathrm{V}$ & Japan & & (32) \\
\hline 45 & $\mathrm{~F}$ & RARS & $+8,+15$ & Simultaneously & $O, G, S, F$ & Japan & & (33) \\
\hline 41 & $\mathrm{~F}$ & RARS & +8 & At diagnosis & $\mathrm{O}, \mathrm{I}, \mathrm{S}, \mathrm{F}$ & Japan & & (4) \\
\hline 54 & $\mathrm{~F}$ & RA & +8 & 1y after MDS & $\mathrm{O}, \mathrm{G}, \mathrm{S}, \mathrm{F}, \mathrm{P}$ & Japan & *2 & (5) \\
\hline 23 & $\mathrm{~F}$ & RA & +8 & 18y before MDS & O,G,I,S & Japan & & (6) \\
\hline 34 & $\mathrm{~F}$ & RA & +8 & 3y after MDS & $\mathrm{O}, \mathrm{G}, \mathrm{I}, \mathrm{F}, \mathrm{U}$ & Japan & & (7) \\
\hline 50 & M & RARS & +8 & Simultaneously & $\mathrm{O}, \mathrm{G}, \mathrm{I}, \mathrm{S}, \mathrm{F}, \mathrm{P}$ & Italy & & (8) \\
\hline 59 & $M$ & RA & +8 & $1 \mathrm{~m}$ after MDS & $\mathrm{O}, \mathrm{G}, \mathrm{S}, \mathrm{F}$ & Japan & & (9) \\
\hline 50 & $\mathrm{~F}$ & RA & Complex with +8 & ND & $\mathrm{O}, \mathrm{G}, \mathrm{I}, \mathrm{F}, \mathrm{A}, \mathrm{P}$ & Korea & & (10) \\
\hline 39 & $\mathrm{~F}$ & RAEB-T & -7 & $4 \mathrm{y}$ before MDS & $\mathrm{O}, \mathrm{G}, \mathrm{I}, \mathrm{S}, \mathrm{U}$ & Germany & *1 & (17) \\
\hline 39 & M & RA & +8 & Simultaneously & $\mathrm{O}, \mathrm{G}, \mathrm{I}, \mathrm{F}, \mathrm{A}, \mathrm{V}$ & Japan & & (34) \\
\hline 25 & M & RA & +8 & ND & O,G,I,S & Japan & & (13) \\
\hline 41 & $\mathrm{~F}$ & RA & Complex with +8 & $17 y$ before MDS & $\mathrm{O}, \mathrm{G}, \mathrm{I}, \mathrm{S}$ & Japan & & (13) \\
\hline 67 & M & CMML & ND & ND & O.G.S.F.A.E & USA & & (11) \\
\hline 35 & $M$ & MDS-AL & -7 & 3y before MDS & $\mathrm{V}(\mathrm{CNS})$ & Italy & *1 & (16) \\
\hline 74 & $\mathrm{~F}$ & RA & Complex with +8 & ND & O,I,T & Japan & *2 & (12) \\
\hline 36 & $\mathrm{~F}$ & RA & $\operatorname{dup}(1)(q 12 ; q 44),+8$ & ND & $\mathrm{I}, \mathrm{S}, \mathrm{T}$ & Japan & *2 & (12) \\
\hline 31 & $\mathrm{~F}$ & RA & +8 & ND & I,V & Japan & & (12) \\
\hline 56 & $\mathrm{~F}$ & RA & +8 & $6 y$ before MDS & $\mathrm{O}, \mathrm{G}, \mathrm{S}, \mathrm{F}$ & Japan & & (35) \\
\hline 64 & $M$ & RA & +8 & Simultaneously & $O, G, I$ & Japan & & (36) \\
\hline 28 & $\mathrm{~F}$ & RA & +8 & $5 y$ before MDS & O,G,I,S & Japan & & (37) \\
\hline 39 & $\mathrm{~F}$ & RA & $+8,+9$ & 10y before MDS & O,G,I,S & Japan & & (37) \\
\hline 10 & $\mathrm{~F}$ & RAEB & Ring 6 & Simultaneously & O,F,I,S & Japan & *3 & (21) \\
\hline 55 & $M$ & RAEB & Complex & $3 \mathrm{~m}$ after MDS & O,G,S,Eso & Japan & & (38) \\
\hline 27 & $\mathrm{~F}$ & RAEB & +8 & $8 y$ before MDS & $\mathrm{O}, \mathrm{G}, \mathrm{S}, \mathrm{F}$ & Japan & *3 & (20) \\
\hline 49 & M & RA & Constitutional trisomy 8 & $4 \mathrm{y}$ before MDS & $\mathrm{O}, \mathrm{G}, \mathrm{I}, \mathrm{T}, \mathrm{A}$ & Japan & & (39) \\
\hline 45 & $\mathrm{~F}$ & RAEB-T & Complex with $+\mathrm{i}(8 \mathrm{q})$ & $8 y$ before MDS & $\mathrm{O}, \mathrm{G}, \mathrm{I}, \mathrm{A}, \mathrm{S}, \mathrm{F}$ & Israel & *1 & (18) \\
\hline 54 & M & RA? & +8 & Simultaneously & $G, A, S$ & UK & *2 & (19) \\
\hline 69 & M & RAEB-T & Complex with $-5,+8$ & Simultaneously & $\mathrm{O}, \mathrm{I}, \mathrm{S}, \mathrm{F}$ & Japan & & (40) \\
\hline \multirow[t]{2}{*}{76} & $\mathrm{~F}$ & RA & +8 & 3y after MDS & $\mathrm{O}, \mathrm{G}, \mathrm{I}, \mathrm{S}, \mathrm{F}$ & Japan & & Present \\
\hline & & & & & $\mathrm{O}, \mathrm{G}, \mathrm{I}, \mathrm{S}, \mathrm{F}, \mathrm{A}$ & & & \\
\hline 75 & $M$ & RAEB & +8 & 1y before MDS & $P$ & Japan & & Present \\
\hline 67 & $\mathrm{~F}$ & RAEB & Complex with del $(5 q),+8$ & Simultaneously & $\mathrm{O}, \mathrm{I}, \mathrm{F}$ & Japan & & Present \\
\hline
\end{tabular}

Abbreviations: RA, refractory anemia; RARS, RA with ringed sideroblasts; RAEB, RA with excess blasts; RAEB-T, RAEB in transformation; ND, not described; 'complex' indicates abnormalities involving more than two chromosomes; O, oral ulcers; G, genital ulcers; I, intestinal ulcers; Eso, esophageal ulcers; S, skin lesions; F, fever; A, arthralgia; $P$, positive pathergy test; $T$, thrombosis; $U$, uvenitis; $V$, vasculitis. *1; chlorambucil was used to treat BD. *2; G-CSF was used to treat MDS. *3; cord blood transplantation for MDS was performed.

similar to the other two cases. Bone marrow cells of all our cases had chromosomal abnormalities with trisomy 8 .

As mentioned above and reported by others, trisomy 8 is likely a risk factor for $\mathrm{BD}$, especially the intestinal type, in patients with MDS (12). Excessive production of inflammatory cytokines and abnormal neutrophil functions are frequently observed in MDS $(22,23)$. These abnormalities can possibly cause the skin and mucosal inflammatory lesions observed in $\mathrm{BD}$, because the abnormal neutrophil functions, the overproduction of inflammatory cytokines as well as other immunological abnormalities are thought to be involved in the etiology of BD (14). Granulocyte colonystimulating factor, which may stimulate the production of inflammatory cytokines, administered for cytopenia in MDS, could elicit or aggravate the symptoms of BD (12). A number of case reports have implicated the relationship between $\mathrm{BD}$ and MDS with trisomy 8 , but no reasonable etiological link between them has been proposed. Chen et al (24) recently analyzed the gene expression pattern in purified CD 34-positive hematopoietic progenitor cells obtained from MDS patients with either trisomy 8 or monosomy 7 . In cases with trisomy 8 , up-regulated genes included those primarily involved in immune and inflammatory responses (such as TGF-beta, TGF-beta receptor, interleukin-6, interleukin-7 receptor and VCAM-1), while genes upregulated in cells with monosomy 7 did not include these genes but included those involved in leukemia transformation (HOX9A, BRCA2, and PLAB) and apoptosis (TRAIL 
and TRAIL-DR5) (24). This expression profile of CD34positive cells with trisomy 8 may be related to the pathogenesis of BD-like symptoms occurring in MDS patients with this chromosomal abnormality.

Trisomy 8 is a cytogenetic abnormality frequently observed not only in MDS but also in myeloproliferative disorders (MPD) such as polycythemia vera, idiopathic myelofibrosis, essential thrombocythemia and chronic myelogenous leukemia (CML) as well as in acute myeloid leukemia (AML) (25). However, BD-like symptoms are not common in patients with MPDs (26), except for those with chronic myelogenous leukemia treated with interferons (27-30). In these CML patients, interferons might induce BD-like symptoms by activating neutrophil functions (27-30). In AML patients, BD-like symptoms are not common. In these patients, the number of mature neutrophils is usually decreased, or their function may be impaired; this may explain why BDlike symptoms are rare. In fact, in our Case 3, intestinal hemorrhage was diminished after leukemic transformation.
Apart from BD, some MDS patients develop other immune-mediated complications such as vasculitis, Sweet's syndrome, immune thrombocytopenia and Hashimoto's thyroiditis (31). Billstrom et al reported that the incidence of chromosomal abnormalities is higher in these MDS patients than in those without immune-mediated complications (31). To date, however, no clear relationship between trisomy 8 and immune-mediated complications other than BD has been documented in MDS patients. In our Case 2, transient thrombocytopenia and CK elevation were observed in each attack, which may be related to some immune-mediated mechanisms.

In conclusion, for hemorrhagic intestinal ulcers observed in $\mathrm{BD}$ patients, the possibility of underlining clonal hematological disorders should be considered. On the other hand, if MDS patients have fever with either abdominal pain or melena, caution should be taken for the possibility of complications with intestinal BD. Further studies are needed to clarify the association between BD and MDS with trisomy 8.

\section{References}

1. Catenacci DV, Schiller GJ. Myelodysplasic syndromes: A comprehensive review. Blood Rev 19: 301-319, 2005.

2. Nehashi Y, Torii Y, Yaguchi M, Itoh Y, Ohyashiki K, Toyama K. Incomplete-form of Behçet disease in a case of monopathic myelodysplastic syndrome presenting as a thrombocytopenia. Rinsho Ketsueki 29: 1097-1102, 1988 (in Japanese).

3. Nakayama $S$, Ishikawa $T$, Yabe $H$, Nagai $K$. Refractory anemia complicated by Behçet's disease--report of three cases. Rinsho Ketsueki 30: 530-534, 1989 (in Japanese).

4. Chyuma Y, Utsunomiya A, Saito T, Hanada S, Nishimata H, Arima T. Hemolytic anemia complicated with Behçet's disease and myelodysplastic syndrome. Rinsho Ketsueki 33: 333-337, 1992 (in Japanese).

5. Yano K, Eguchi K, Takashima H, et al. Case of myelodysplastic syndrome associated with Behçet's disease. Nippon Naika Gakkai Zasshi 84: 614-616, 1995 (in Japanese).

6. Yano K, Eguchi K, Migita K, et al. Behçet's disease complicated with myelodysplastic syndrome: a report of two cases and review of the literature. Clin Rheumatol 15: 91-93, 1996.

7. Ohno E, Ohtsuka E, Watanabe K, et al. Behçet's disease associated with myelodysplastic syndromes. A case report and a review of the literature. Cancer 79: 262-268, 1997.

8. Della Rossa A, Tavoni A, Tognetti A, Testi C, Bombardieri S. Behçet's disease with gastrointestinal involvement associated with myelodysplasia in a patient with congenital panhypopituitarism. Clin Rheumatol 17: 515-517, 1998.

9. Nawata R, Shinohara K, Takahashi T, Yamada T, Katsuki K. Refractory anemia with trisomy- 8 complicated by Behçet's disease with elevated levels of inflammatory cytokines. Rinsho Ketsueki 40: 1100-1104, 1999 (in Japanese).

10. Oh EJ, Yoon JS, Park YJ, Cho CS, Kim BK. Behçet's disease associated with myelodysplastic syndrome: a case report. J Korean Med Sci 14: 685-687, 1999.

11. Karuvannur S, Lipstein E, Brennessel D, Rosner F. Atypical Behçet's syndrome in a patient with myelodysplastic syndrome. Mt Sinai J Med 68: 403-405, 2001.

12. Kimura S, Kuroda J, Akaogi T, Hayashi H, Kobayashi Y, Kondo M. Trisomy 8 involved in myelodysplastic syndromes as a risk factor for intestinal ulcers and thrombosis-Behçet's syndrome. Leuk Lymphoma 42: 115-121, 2001.

13. Ogawa $H$, Kuroda $T$, Inada $M$, et al. Intestinal Behçet's disease associated with myelodysplastic syndrome with chromosomal trisomy 8-a report of two cases and a review of the literature. Hepatogastroenterology 48: 416-420, 2001.

14. Evereklioglu C. Current concepts in the etiology and treatment of Behçet disease. Surv Ophthalmol 50: 297-350, 2005.

15. Hirohata T, Kuratsune M, Nomura A, Jimi S. Prevalence of Behçet's syndrome in Hawaii. With particular reference to the comparison of the Japanese in Hawaii and Japan. Hawaii Med J 34: 244-246, 1975.

16. Sirianni MC, Barbone B, Monarca B, Nanni M, Lagana B, Aiuti F. A case of Behçet's disease complicated by visceral Leishmaniasis and myelodysplasia: clinical considerations. Haematologica $\mathbf{8 6}$ : 1004-1005, 2001.

17. Bangerter M, Griesshammer M, von Tirpitz C, et al. Myelodysplastic syndrome with monosomy 7 after immunosuppressive therapy in Behçet's disease. Scand J Rheumatol 28: 117-119, 1999.

18. Eder L, Rozenbaum M, Boulman N, et al. Behçet's disease, myelodysplastic syndrome, trisomy 8, gastroenterological involvement —an association. Clin Exp Rheumatol 23: S91-S95, 2005.

19. Kuttikat A, Haskard D, Chakravarty K. Behçet's disease associated with trisomy 8 in a male Caucasian patient from Great Britain-a case report. Clin Exp Rheumatol 23: S108-S109, 2005.

20. Tomonari A, Tojo A, Takahashi T, et al. Resolution of Behçet's disease after HLA-mismatched unrelated cord blood transplantation for myelodysplastic syndrome. Ann Hematol 83: 464-466, 2004.

21. Yamato K. Successful cord blood stem cell transplantation for myelodysplastic syndrome with Behçet disease. Int J Hematol 77: 82-85, 2003.

22. Hsu HC, Lee YM, Tsai WH, et al. Circulating levels of thrombopoietic and inflammatory cytokines in patients with acute myeloblastic leukemia and myelodysplastic syndrome. Oncology 63: 64-69, 2002.

23. Martin S, Baldock SC, Ghoneim AT, Child JA. Defective neutrophil function and microbicidal mechanisms in the myelodysplastic 
disorders. J Clin Pathol 36: 1120-1128, 1983.

24. Chen G, Zeng W, Miyazato A, et al. Distinctive gene expression profiles of CD34 cells from patients with myelodysplastic syndrome characterized by specific chromosomal abnormalities. Blood 104: 4210-4218, 2004.

25. Bench AJ, Cross NC, Huntly BJ, Nacheva EP, Green AR. Myeloproliferative disorders. Best Pract Res Clin Haematol 14: 531-551, 2001.

26. Kobune M, Kato J, Kuribayashi K, et al. Essential thrombocythemia associated with incomplete type intestinal Behçet disease during hydroxyurea treatment. Rinsho Ketsueki 46: 1136-1140, 2005 (in Japanese).

27. Karti SS, Ovali E, Ratip S, et al. Effect of interferon-alpha (2a) on neutrophil adhesion and phagocytosis in chronic myeloid leukemia and Behçet's disease. Clin Rheumatol 21: 211-214, 2002.

28. Vaiopoulos G, Terpos E, Viniou N, Nodaros K, Rombos J, Loukopoulos D. Behçet's disease in a patient with chronic myelogenous leukemia under hydroxyurea treatment: a case report and review of the literature. Am J Hematol 66: 57-58, 2001.

29. Budak-Alpdogan T, Demircay Z, Alpdogan O, et al. Skin hyperreactivity of Behçet's patients (pathergy reaction) is also positive in interferon alpha-treated chronic myeloid leukaemia patients, indicating similarly altered neutrophil functions in both disorders. Br J Rheumatol 37: 1148-1151, 1998.

30. Budak-Alpdogan T, Demircay Z, Alpdogan O, et al. Behçet's disease in patients with chronic myelogenous leukemia: possible role of interferon-alpha treatment in the occurrence of Behçet's symptoms. Ann Hematol 74: 45-48, 1997.

31. Billstrom R, Johansson H, Johansson B, Mitelman F. Immunemediated complications in patients with myelodysplastic syndromes-clinical and cytogenetic features. Eur J Haematol 55: 4248, 1995.
32. Takishita N, Horiuchi T, Hato T, Fujita S, Kobayashi Y. Myelodysplastic syndrome complicated with Behçet's disease. Ehime Igaku 11: 39-43, 1991 (in Japanese).

33. Yoshizawa Y, Hirai A, Izaki S, Kitamura K. Behçet's disease associated with myelodysplastic disorder. Hifu Rinsho 34: 1585-1589, 1992 (in Japanese).

34. Tanaka E, Nishinarita M, Uesato M, Kamatani N. A case of intestinal Behçet's disease with abnormal ossification complicated by myelodysplastic syndrome, symptoms revealed after the perforation of ileum ulcer. Ryumachi 40: 711-718, 2000 (in Japanese).

35. Kageyama H, Hidaka T, Kondou S, Tamura K. Intestinal Behçet's disease associated with myelodysplastic syndrome. Jpn J Clin Hematol 34: 1288, 1993 (in Japanese).

36. Fujita H, Kiriyama M, Kawamura T, et al. Massive hemorrhage in a patient with intestinal Behçet's disease: report of a case. Surg Today 32: 378-382, 2002.

37. Adachi Y, Tsutsumi A, Murata H, et al. Behçet's disease accompanied by myelodysplastic syndrome with trisomy 8: two case reports and a review of 15 Japanese cases. Mod Rheumatol 13: 9094, 2003.

38. Handa T, Arai Y, Mitani K. Myelodysplastic syndrome associated with intestinal tract-type Behçet disease characterized by an esophageal ulcer. Rinsho Ketsueki 45: 1135-1137, 2004 (in Japanese).

39. Ando S, Maemori M, Sakai H, Shiraishi H, Sakai K, Ruhnke GW. Constitutional trisomy 8 mosaicism with myelodysplastic syndrome complicated by intestinal Behçet disease and antithrombin III deficiency. Cancer Genet Cytogenet 162: 172-175, 2005.

40. Tsubata R, Suzuki F, Sugihara T, et al. An autopsy case of intestinal Behçet's disease with sacroiliitis accompanied by myelodysplastic syndrome with trisomy 8. Nihon Rinsho Meneki Gakkai Kaishi 28: 48-55, 2005 (in Japanese).

(C) 2006 The Japanese Society of Internal Medicine http://www.naika.or.jp/imindex.html 